\title{
Transfills Medical Gas
}

National Cancer Institute

\section{Source}

National Cancer Institute. Transfills Medical Gas. NCI Thesaurus. Code C126091.

The process of transfilling in order to produce a medical gas product. 